\title{
A FORMAÇÃO PROFISSIONAL EM EDUCAÇÃO FÍSICA PERMEADA PELAS TECNOLOGIAS DE INFORMAÇÃO E COMUNICAÇÃO NO CENTRO DE EDUCAÇÃO FÍSICA E DESPORTOS DA UNIVERSIDADE FEDERAL DE SANTA MARIA
}

\author{
Paula Bianchi* \\ Marli HatJe $^{* *}$
}

\section{RESUMO}

O objetivo central deste artigo é analisar a formação de professores de Educação Física permeada pelas Tecnologias de Informação e Comunicação (TICs) no Centro de Educação Física e Desportos da UFSM. A partir da análise teórica sobre conceitos e características das TICs e formação de professores e do Projeto Político Pedagógico do Curso de Educação Física-Licenciatura do CEFD/UFSM e de entrevistas, verificou-se que as TICs estão reconfigurando as atuais formas de espaço e tempo. Assim, elas transformam as representações sociais, de trabalho e o modo como se concebem e constroem as qualificações. Essa realidade requer uma "nova" atitude do professor, pessoas mais qualificadas, infra-estrutura e metodologias problematizadoras.

PALAVRAS-CHAVE: Educação Física - formação de professor - Tecnologia de Informação e Comunicação

\section{CONSIDERAÇÕES INICIAIS}

$\mathrm{O}$ desenvolvimento e o avanço tecnológico, bem como o aparecimento de modernos meios de telecomunicações, estão reconfigurando as atuais formas de espaço e tempo, levando-nos a constantes e rápidas transformações nas formas de representação sobre nós mesmos, sobre as formas de trabalho e sobre a maneira como se concebem e constroem as qualificações. Essas mudanças interferem e modificam o modo como se processa e as formas como se desenvolve as pesquisas em todas as áreas do conhecimento científico, entre elas, a Educação Física, que integra as áreas da saúde e da educação.

\footnotetext{
* Especialista em Educação Física Escolar pelo CEFD/UFSM.

** $\quad$ Prof $^{\mathrm{a}}$ Dr $^{\mathrm{a}}$ Adjunta do CEFD/UFSM.
} 
Segundo Hatje et al. (2004, p. 22), "essa emergente realidade requer do professor, novas e constantes aprendizagens, pois, pairam sobre ele características como um dos principais mediadores entre a sociedade e as TICs". O educador inserido, nessa realidade interdisciplinar, tem papel fundamental, no processo de aquisição do conhecimento, desenvolvendo um ecossistema comunicacional, onde trata das relações entre professor e aluno, Instituição de Ensino (IE) e comunidade, a mídia e seu público. A dimensão das TICs no que se refere a sua importância e influência na sociedade, com ênfase no sistema escolar, tem sido objeto de discussão e estudo em diferentes Instituições de Ensino Superior (IES).

As possibilidades de uso das TICs são diversas. Dependendo da criatividade do usuário e de sua capacidade cognitiva, podemos multiplicar o já elevado número de alternativas de uso. Diante do exposto e da necessidade de ampliar as discussões no CEFD da UFSM, em face de ênfase dada às TICs nos novos desenhos curriculares, optamos por analisar a importância das TICs na formação de professores de Educação Física no CEFD/ UFSM, bem como conhecer a realidade do Curso, no que tange à formação profissional e à atuação profissional, quanto ao uso de novas metodologias de ensino, novas temáticas e novos recursos didáticos. A preocupação é trazer elementos para conhecimento e reflexão do contexto das TICs na formação de professores de Educação Física no CEFD/UFSM.

$\mathrm{O}$ estudo caracterizou-se como qualitativo descritivo. Foram entrevistados oito docentes, sete da UFSM e um do Centro Universitário Franciscano, e um técnico administrativo do CEFD/UFSM. ${ }^{1}$ Para a realização da coleta e análise de dados foram estabelecidos os seguintes encaminhamentos: a) revisão bibliográfica, buscando identificar os conceitos, as características e as funções das TICs na sociedade contemporânea; b) revisão bibliográfica, buscando identificar os conceitos e as características sobre a Formação de Professores de Educação Física; c) análise do Projeto Político Pedagógico (PPP) do Curso de Licenciatura em Educação Física do CEFD/UFSM; d) entrevista semi-estruturada aplicada aos docentes e técnico-administrativo, e) análise dos resultados.

As discussões envolvendo as TICs ainda podem ser consideradas recentes, no meio universitário, inclusive, na UFSM, e, particularmente, no CEFD. Nesta pesquisa, buscamos, sobretudo, levantar dados e construir um referencial teórico preliminar, a partir de uma realidade 
vivida numa IES: a UFSM. O diálogo com docentes da Universidade iniciou pela conceituação e pelas características das TICs.

\section{TICS: CONCEITOS E CARACTERÍSTICAS}

Observamos, nas análises, que as TICs podem ser consideradas um conjunto de ferramentas tecnológicas, cada vez mais presentes no cotidiano, e imprescindível para um grande número de profissionais de diferentes áreas de atuação. Compõem as TICs ferramentas tecnológicas que podem e/ou são utilizadas na educação como o quadro, o giz, os materiais didáticos, as novas TICs formadas pela informática (que abrange todo tipo de computador e periféricos), também as teleconferências, as videoconferências e as mídias tradicionais (mídia impressa, rádio, televisão, telefone).

Uma das principais características das TICs é a mudança que ela gera nos padrões de trabalho, de tempo, de lazer, de educação e de saúde da sociedade. Desse modo, considera-se a tecnologia não como um fenômeno autônomo e determinante, mas como fruto da atividade humana, portanto, inserida, num contexto sociocultural, que enquanto influencia a sociedade é, ao mesmo tempo, transformada por ela. Então é fundamental que a IES, ao compreender que não é possível falar de "neutralidade" da tecnologia, proponha reflexões acerca do real significado das TICs, buscando discutir se estará a tecnologia tornando-se tão central na vida da sociedade a ponto de se tornar um fim em si mesma. Essas mudanças vêm ao encontro dos objetivos de aprendizagem crítica e permitem o desenvolvimento de ações educacionais, a partir de concepções de aprendizagem que visam formar sujeitos autônomos.

Os computadores e os sistemas digitais produziram um salto qualitativo importante no modo de gerar e receber uma informação, garantindo acesso rápido às informações e a uma variedade delas. As ferramentas tecnológicas, com suas cores e sons, podem atenuar as diferenças existentes entre o universo educacional e o mundo externo (Depoimento de Professor, 2006).

O uso das TICs, quando bem conduzido, pode promover a interação entre professores e alunos, intercâmbio de informações e 
experiências, agindo como uma "janela para o mundo", isto é, permite que o educando conquiste outros espaços. Uma das principais características da educação, envolvendo as TICs é o de promover o acesso às informações que acaba provocando uma descentralização do poder de comunicar em sala de aula, anteriormente, centrado na figura do professor. Nessa nova conjuntura, o aluno adquire maior autonomia, principalmente, na Educação a Distância (EAD) que consiste em oportunizar a formação profissional eliminando as barreiras geográficas e de tempo, buscando garantir qualidade ao processo de ensino-aprendizagem.

A descentralização, no entanto, deve ser orientada, supervisionada pelo professor, sistemática, com avaliação, auto-avaliação e com o aluno assumindo o compromisso de compartilhar suas experiências e de se envolver, responsavelmente, na execução do trabalho. A inclusão das TICs, na educação, deve ser um processo gradativo, construído com a participação das pessoas que fazem a educação (Depoimento de Professor, 2006).

O uso das tecnologias é irreversível e tornou-se fundamental no processo educacional moderno, além de ser indispensável nos modos de produção. No entanto, o campo da educação e da Educação Física Escolar, ainda apresenta resistência ao uso das tecnologias, o que se dá, principalmente, pela falta de uma formação profissional adequada que capacite os professores a utilizar e desenvolver, criticamente, um estilo próprio de atuar com as TICs.

Através, das respostas dos professores, percebemos que o ensino, na UFSM, ainda está centrado no uso das ferramentas tradicionais (mídias tradicionais, aulas expositivas e centradas no professor) e que as TICs são empregadas como simples recursos técnicos para elaborar e ministrar a aula. Entendemos, a partir dessa constatação, que o uso das tecnologias não é tão simples e que exige uma formação técnica e crítica para sua aplicação.

As tecnologias caracterizam-se como uma ciência que podem ser utilizadas como Ferramentas, ou seja, como um meio auxiliar no processo de criação (quando se utiliza uma tecnologia com os recursos que ela possui) e como Hiper-ferramentas, quando emprega-se, uma 
tecnologia como um instrumento para ampliar e aperfeiçoar o conhecimento da área em questão, isto é, quando desenvolve o pensamento, a sensorialização para estar além de reprodução, capaz de gerar conhecimento elaborado sobre determinado assunto (Depoimento de Professora, 2006).

Tendo em vista que a deficiente capacitação dos professores que atuam na formação profissional é um dos motivos para as TICs serem pouco adotadas no processo de ensino-aprendizagem, docentes entrevistados mencionaram projetos do Ministério da Educação (MEC) ${ }^{2}$ que têm por objetivos melhorar a qualidade da formação e atuação dos professores no país.

Como já mencionado, a utilização das TICs na formação profissional ainda é limitada, entendimento compartilhado com docentes que participaram da pesquisa, conforme os depoimentos a seguir. No entanto, os investimentos institucionais e, sobretudo, pessoais, as estratégias a serem adotadas ou assumidas pelos docentes apontam para perspectivas otimistas quanto a uma melhor formação dos futuros profissionais com o auxílio das TICs. O caminho, apesar disso, requer dedicação, conhecimento diferenciado e constante atualização.

\section{O USO DIDÁTICO-PEDAGÓGICO DAS TICS: ESTRATÉGIAS E PERSPECTIVAS}

O uso das TICs na formação profissional divide os docentes entrevistados em três grupos distintos: a) aquele que já está utilizando as TICs, mas, apenas como ferramenta para melhor ministrar a sua aula; b) aquele que já usa e busca ampliar a utilização desses recursos elaborando/ministrando sua aula com o auxílio de blog's, ${ }^{3}$ plataforma virtual, diário virtual, endereço eletrônico coletivo, programas de Software ${ }^{4}$ livre (por exemplo, Ambiente de Multimídia para Educação Mediada pela Tecnologia), teleconferências e videoconferências; c) aquele grupo que apenas está começando a introduzir as TICs em seu cotidiano profissional e admite que o uso deve ser melhorado e ampliado.

Mesmo diante do exposto, a inserção das TICs nos desenhos curriculares dos Cursos de Educação Física ainda é lenta, mas as perspectivas são boas: 
Estou utilizando, em uma disciplina, um coletivo de endereços eletrônicos, onde mantemos contato e trocamos informações. A comunicação é semanal e, refere-se sempre a algum texto enviado ao grupo. Toda semana, os alunos recebem um novo texto, e enviam um comentário para o professor que, a partir desse comentário, amplia as discussões. Tudo acontece virtualmente. Mas, reconheço que é necessário mais informações sobre o uso de diferentes tecnologias na educação, por isso aposto na teleconferência como importante recurso na educação (Depoimento de Professor, 2006).

Acredita-se que, cada vez mais, os docentes irão aderir às tecnologias no processo educativo, em geral, sempre buscando implementá-las, como ferramentas complementares, motivadoras e dinâmicas, além de amplamente, interativas entre aluno-professor-aluno (Depoimento de Professora, 2006).

A formação do professor deve ser vista como um processo contínuo, considerando a importância de um novo fazer pedagógico, isso justifica a preocupação relacionada à oferta de Cursos de Formação Continuada para os professores universitários.

A capacitação profissional, em IES, é de extrema importância, conforme argumenta um dos professores entrevistados:

Utilizo como principal recurso didático a palavra, e tenho receio com os problemas técnicos que podem ocorrer durante a utilização das TICs. Quando ocorrem esses problemas, elas dificultam o trabalho. Acredito que a aplicação das TICs está diretamente relacionada com o domínio do seu uso. No meu caso só utilizarei aquelas tecnologias que domino, caso contrário, estarei correndo riscos! (Depoimento de Professor, 2006).

Não se pode pensar que a introdução das tecnologias possa ocorrer sem profundas mudanças nos modos de ensinar e na própria concepção e organização dos sistemas educativos, gerando profundas modificações na cultura do Ensino Escolar e Superior. A qualificação profissional é apontada como um dos principais caminhos na construção de conhecimento, na busca por maiores informações e, principalmente, no preenchimento de lacunas na formação profissional. 
Existe uma preocupação evidente dos professores em preparar o aluno para interagir com o mundo (digital) e fornecer subsídios para que ele possa ter autonomia diante das tecnologias. Além disso, os professores apresentam uma perspectiva bastante otimista, em relação às possibilidades de usar as TICs em diferentes escalas. Seja na educação, na questão de articulação de questões identitárias, nas questões públicas ou na formação profissional e pessoal dos sujeitos. Ao utilizarmos as TICs, é fundamental gerar uma consciência reflexiva sobre os aspectos (bons e ruins) que as envolvem e não, simplesmente, negá-las por negálas, a partir de críticas subjetivas e superficiais.

$\mathrm{Na}$ literatura, existem diversos estudos e pesquisas que tratam do uso das TICS no processo ensino-aprendizagem, sobretudo, as vantagens e as desvantagens no processo educacional. Nesta pesquisa, buscamos elucidar, junto aos docentes do CEFD/UFSM, algumas questões relevantes e imprescindíveis na formação profissional para uma atuação profissional eficiente.

\section{O USO DIDÁTICO-PEDAGÓGICO DAS TICS: VANTAGENS E DESVANTAGENS}

No campo da educação, o uso das TICs tem gerado muita discussão acerca das suas vantagens e desvantagens. De acordo com Belloni (2001, p. 68), o impacto do avanço tecnológico, entendido como um processo social sobre processos e instituições sociais (educação, comunicação, trabalho, lazer, relações pessoais e familiares, cultura, imaginário e identidade, etc.), tem sido muito forte, embora percebido de modos diversos e estudado a partir de diferentes abordagens.

\section{AS VANTAGENS DO USO DAS TICS:}

a) os professores reconhecem a importância das TICs, como ferramentas metodológicas e pedagógicas que podem ser introduzidas no processo de ensino-aprendizagem, estimulando a criação de ambientes educativos mais dinâmicos, interativos e desafiadores;

b) as TICs provocaram uma reconfiguração do tempo e do espaço, através das suas características (interatividade, instantaneidade, boa qualidade técnica e dinamicidade); 
C) promoveram a ampliação da Inclusão Digital ${ }^{5}$ através, da democratização de acesso às TICs, da diminuição dos preços das tecnologias e da simplificação do manuseio;

d) contribuíram para o desenvolvimento da independência do aluno. Nessa realidade, o aluno também é o construtor da sua formação profissional;

e) promoveram transformações nas formas de aquisição do conhecimento científico e nas condições de trabalho docente, descentralizando o ensino da figura do professor como fonte principal de informação, ao mesmo tempo "tirando" o professor do comodismo habitual, levando-o a repensar a sua prática pedagógica;

f) facilitaram a criação e manutenção de Cursos de Formação Continuada em diversas áreas de atuação, além de ampliarem o sistema educacional no país, levando para regiões mais isoladas, cursos de formação e atualização profissional.

\section{AS DESVANTAGENS NO USO DAS TICS:}

a) as TICs podem levar a uma educação dispersiva, de má-qualidade, quando conduzida sem orientação do professor;

b) pode haver uma inversão de valores e de papéis, em relação às mídias, criando ao redor delas, um encantamento, como se as TICs fossem capazes, por si só, de solucionar todos os problemas e, até substituir a presença do professor;

c) saber como utilizar as diferentes tecnologias e qual metodologia o professor deve utilizar para melhor aproveitar esses recursos/alternativas pedagógicas;

d) descobrir a medida ideal entre o ensino presencial, a educação a distância e o uso das diversas tecnologias;

e) o acesso às TICs, ainda, é limitado por questões econômicas, geográficas e culturais.

A tecnologia facilita o acesso à informação, mas não garante a democratização das informações. Há pessoas que vão construir um conhecimento mais elaborado, a partir das TICs, outras apenas vão reproduzir essas informações.

O mundo caminha para os tecno-integrados, que dominam o mundo digital e os excluídos que não pertencem ao mundo digital. O avan- 
ço das TICs modifica o modo de educar e aprender, além do modo de produção. Os novos excluídos sociais serão aquelas pessoas que por não estarem integradas às TICs, não encontrarão emprego e serão marginalizadas. A geração de trabalho e de renda estará fortemente relacionada ao uso e domínio das tecnologias (Depoimento de Professor, 2006).

Essas ações são fortemente influenciadas pelos profissionais que usam as TICs. Por isso, na seqüência do trabalho, entendemos oportuno, discutir a situação específica da formação profissional em Educação Física no CEFD/UFSM, considerando o repertório teórico e as entrevistas realizadas. Percebemos que, ainda, são poucos os estudos e as relações específicas de uso das TICs na formação e atuação profissional em Educação Física, mas é um tema que vai, lentamente, conquistando seu espaço no meio acadêmico. Os entrevistados, por exemplo, trataram a questão de forma geral, ou seja, as TICs na formação de professores na área educacional, e ao final do trabalho a pesquisadora realizou o exercício de transpor essa macro realidade para a Educação Física.

\section{AS TICS E A FORMAČ̃̃O PROFISSIONAL EM EDUCAÇÃO FÍSICA}

Uma questão que está gerando discussões entre os professores, pesquisadores e as IES é a influência das TICs na formação profissional. Nos cursos de Educação Física isso não é diferente. ${ }^{f}$ Será possível a educação manter-se imparcial a essa questão, ou seja, restringir-se apenas a transmitir os conteúdos programáticos sem estabelecer relações com o contexto social em que está inserida? Será possível preparar o acadêmico para usar e dominar (no sentido mais amplo) as TICs? E, como deve proceder a educação para preparar a sociedade de forma que ela domine as tecnologias que permeiam, crescentemente, todos os setores da vida e possa aproveitá-las? São questionamentos formulados com o propósito de entender melhor as possibilidades de uso e os riscos das tecnologias, buscando encontrar subsídios para enfrentar as transformações do cotidiano humano e proporcionar uma formação profissional que atenda a essas mudanças, sem deixar de lado o seu caráter educativo. 
Busca-se um equilíbrio entre o uso das tecnologias e as práticas pedagógicas, reduzindo dessa forma a distância entre a escola, a sociedade e o mercado de trabalho. No entanto, não se quer afirmar com isso que a Educação Física deva se adequar às TICs ou às exigências mercadológicas, pois, este é um processo que ocorrerá naturalmente. Pretendemos sim chamar a atenção para o fato de que não se pode negar a amplitude, a repercussão e a importância das tecnologias em qualquer esfera da vida humana.

Os professores que colaboraram com esse estudo afirmam que as TICs auxiliam o aluno e o professor na busca de novas informações, de forma mais rápida e dinâmica. Eles acreditam que as tecnologias sozinhas ou enquanto recursos didáticos não auxiliam na formação profissional crítica, daí é fundamental a orientação do professor no processo de aprendizagem.

As TICs podem auxiliar na formação crítica, dependendo dos objetivos com que elas são empregadas na sociedade. Ninguém se torna consciente ou crítico, simplesmente, pelo fato de ter acesso a mais informações (Depoimento de Professor, 2006).

Nesse sentido, as escolas e as IES enfrentam problemas em comum, entre eles: a) despreparo do professor; b) falta de infra-estrutura e de materiais; e c) falta de incentivos políticos para cursos de capacitação tecnológica. As IES, além disso, têm problemas com as lacunas na grade curricular nos Cursos de Licenciatura. Conforme uma das professoras entrevistadas destaca que:

No momento, em que possa se pensar nas TICs, em todos os níveis escolares, haverá avanços significativos na qualidade da educação. No entanto, isso depende, também, dos interesses de órgãos públicos, que podem apresentar diferentes objetivos: preocupação em formar para o uso pedagógico das TICs, aumentar o número de pessoas matriculadas, através da EAD ou apenas promover a inserção das tecnologias no sistema escolar.

As lacunas existentes na formação e atuação profissional apresentam muitos problemas, seja pela falta de preparo dos professores, pela falta de infra-estrutura ou pela falta de motivação e interesse em inovar na área da formação profissional em nível superior. De maneira 
geral, podemos afirmar que os novos currículos dos cursos de Educação Física não contemplam as TICs. No RS, e na UFSM, em particular, a realidade já é diferente. A temática foi contemplada com uma disciplina específica nos cursos de Licenciatura e Bacharelado. Mesmo, ainda tímidas, as estratégias de ensino começam a se aperfeiçoar e atualizar.

\section{AS TICS NOS NOVOS DESENHOS CURRICULARES DOS CURSOS DE EDUCAÇÃO FÍSICA}

O Curso de Educação Física do CEFD/UFSM, assim como já acontece nas demais IES do país, passou por reformas curriculares, que atingiu a Graduação com a criação de dois cursos de Graduação: Licenciatura implementado em 2005 e Bacharelado, implementado em 2006.

O Projeto Político Pedagógico (PPP), implementado em 2005, do Curso de Educação Física Licenciatura contempla de forma direta as questões envolvendo a mídia, a comunicação e as TICs em uma disciplina denominada "Educação Física e as Novas Tecnologias de Informação e Comunicação". Esta disciplina, também consta no PPP do Curso de Bacharelado. Embora, apresentem os mesmos objetivos, o foco dos conteúdos programáticos está voltado para a escola (no Curso de Licenciatura) e para o esporte e saúde (no Curso de Bacharelado). E, contempla, indiretamente, as questões envolvendo a mídia, a comunicação e as TICs em outras disciplinas do Currículo, na medida em que estas incluem seu uso e a discussão sobre as mídias no processo de ensino-aprendizagem.

O programa da disciplina tem por objetivo preparar os acadêmicos de Educação Física para aprender e educar para e pelas TICs. Mas, o papel de preparar os acadêmicos para utilizar as TICs de forma colaborativa, não está restrito a uma disciplina específica, como afirmam docentes do CEFD, pois, este é um compromisso do corpo docente envolvido com uma formação e atuação abrangente, em um contexto educacional, profundamente influenciado pelas TICs.

Assim, como qualquer outra ferramenta pedagógica, as TICs devem ser utilizadas na Educação Física, principalmente, na Formação de Professor para construir uma nova realidade e sugerir novos caminhos às metodologias fragmentadas. Elas devem possibilitar a união das técnicas que já existem, não as substituindo, mas constituindo novas 
formas de conhecimento, novos valores e significados. São inúmeras as possibilidades metodológicas que os professores podem solicitar para incentivar, dar um caráter prático a esse tema e orientar para o uso colaborativo das tecnologias que, quando, bem conduzido, pode gerar resultados satisfatórios.

O CEFD da UFSM disponibiliza, ao corpo docente, recursos tecnológicos e multimídias, mas há necessidade de aumentar a quantidade, bem como a qualidade dessas tecnologias. Segundo o técnico-administrativo, responsável pela Divisão de Atividades Esportivas (DAE) do CEFD/UFSM, os equipamentos mais solicitados pelos professores são o retroprojetor, o datashow e as câmeras filmadoras. Não existe muita variação na escolha dos recursos tecnológicos solicitados, e o uso das TICs exige, sobretudo, criatividade para que seus recursos não se esgotem no uso repetitivo da técnica.

Um empecilho, na implementação das TICs, é a dificuldade de organização e manutenção desse aparato tecnológico, na sala de aula, visto a carência de recursos humanos capacitados para manusear as tecnologias. Mas um dos objetivos do CEFD é equipar as salas de aula com recursos multimídias.

Percebemos, durante as entrevistas, com professores de diferentes cursos, que o modo como cada curso responde as transformações provocadas pelas tecnologias apresenta disparidades entre si. Contudo, acreditamos que os Cursos de Educação Superior devem incluir as TICs em seus currículos, e aqueles que ainda não o fizeram, serão levados a isso, seja por motivos relacionados à pressão da sociedade, do mercado de trabalho ou dos próprios alunos.

O debate sobre o uso, influência e a importância das TICs na Educação Física é fundamental para o crescimento social e oportuniza (des)construir novos saberes da área em questão e atribuir outros valores às TICs, ampliando e aperfeiçoando, dessa forma, a formação e qualificação profissional em Educação Física.

\section{CONSIDERAÇÕES FINAIS}

Analisar a formação de professores de Educação Física permeada pelas TICs, não é tarefa fácil. Refletir sobre as TICs, como tema emergente, e as mudanças nos Cursos de Educação Física brasileiros, 
desde 2002, requer ainda muitas pesquisas e estudos, de modo a primeiro compreender as especificidades das TICs na área da Saúde e da Educação-Educação Física. A análise permeou a formação profissional de modo geral, embora não fosse esse o objetivo da pesquisa. Mesmo com limitações, buscamos em todo artigo, relacionar a pesquisa à Educação Física, ao CEFD da UFSM.

Diante da atual realidade, podemos afirmar que as Instituições de Ensino (nível fundamental, médio e superior), juntamente com os professores, devem preparar-se para as mudanças significativas, no contexto social, que repercutirão, diretamente, no processo ensino-aprendizagem.

Não há mais como negligenciar a presença e as implicações das TICs no contexto escolar. Os processos educacionais envolvendo a educação continuada são de fundamental importância, principalmente, para aqueles professores que já estão no mercado de trabalho.

Observamos que a implementação das tecnologias necessita, além de bons professores e domínio técnico, de infra-estrutura, isto é, suporte de energia, rede de telefonia e espaço adequado. Em se tratando de tecnologias, não é suficiente ter as ferramentas tecnológicas, mas construir um ambiente de aprendizagem adequado a essa realidade.

A inserção das TICs no ensino não se dá através de uma disciplina específica, nem da exposição de equipamentos audiovisuais na sala de aula. Para garantir trocas de informações em igualdade de condições, pressupõem-se meios e pessoas qualificadas, além de metodologias reflexivas. Para que isso ocorra, devemos atentar para um importante aspecto que é o domínio do uso das diferentes tecnologias. Outro aspecto, bem mais complexo, é estar preparado para fazer uma análise crítica do uso técnico das diferentes mídias, das diversas informações, em vários campos afins e das formas de comunicação possíveis.

Uma das limitações deste trabalho, considerando os objetivos, é o fato de o referencial teórico e as entrevistas realizadas não fazer apenas referência específica à formação e atuação profissional em Educação Física. Tentamos assim, fazer algumas aproximações e referências no sentido de iniciar o processo de discussão na área da Educação Física. Temos consciência que este trabalho tem grande significado para a área educacional e que novas pesquisas, envolvendo a área de Educação Física, ainda devem ser realizadas. 
Professional Education in Physical Education permeated by Information and

Communication Technology at the Physical Education and Sports Center of Universidade Federal de Santa Maria

\begin{abstract}
The main aim of this paper is to take the education program for Physical Education teachers at UFSM university's Center for Physical Education and Sports (CPES) and analyze how it is permeated by information and communication technologies - ICTs. Based on the theoretical analysis of ICT concepts and characteristics, the teacher education program, the political-pedagogical plan for the physical education course at CPES/UFSM, and interviews, we have verified that ICTs are redefining current forms of space and time. In this sense, they transform the social representations for work and the way qualifications are conceived and constructed. This reality requires a "new" attitude from the teacher, better qualified people and problematizing infrastructure and methodologies.

KEYWORDS: Physical Education - teacher education - Information and Communication Technologies.

Formación de profesor de Educación Física permeada por las Tecnologías de Información y Comunicación en el Centro de Educacão Física e Desportos da Universidade Federal de Santa Maria
\end{abstract}

\title{
RESUMEN
}

Analizar la formación de profesores de Educación Física permeada por las TICs en el CEFD/UFSM, a partir del análisis teórico sobre conceptos y características de las Tecnologías de Información y Comunicación (TICs) y formación de profesores; del análisis del Proyecto Político Pedagógico del curso de Educación Física-Licenciatura del CEFD/UFSM y de entrevistas fue el objetivo central de este artículo. Se verificó que las TICs están reconfigurando las actuales formas de espacio y tiempo, transformando las representaciones sociales, de trabajo y el modo como se conciben y construyen las calificaciones. Esa realidad requiere una "nueva" actitud del profesor, personas calificadas, infraestructura y metodologías problematizadoras.

PALABRAS-CLAVE: Educación Física - formación de profesor - Tecnología de Información y Comunicación.

\section{NOTAS}

1 Embora a pesquisa tenha seu foco no Centro de Educação Física e Desportos da UFSM, optamos em entrevistar professores de outros Centros de Ensino da Instituição e um de outra IES, tendo em vista a amplitude do tema, bem como seu caráter inovador. Foi necessário 
ampliar o leque de informações para depois centrar a análise no CEFD. Todos os docentes entrevistados atuam junto as TICs, seja no mercado ou no meio acadêmico.

2 Projeto "Mídias na Educação"; Projetos de Inclusão Digital em escolas públicas; Criação de Secretarias de Educação a Distância; Criação de Cursos de capacitação sobre TICs

3 Espaço virtual utilizado por alguém ou por um grupo de pessoas para veicular informações, conteúdos informativos e estabelecer formas de contato e interação virtual.

4 Nome genérico dado aos programas usados na operação de computadores e dispositivos conectados. Geralmente, são divididos em aplicativos (programas que fazem o trabalho) e softwares de sistemas (que gerenciam o computador).

5 Inclusão Digital caracteriza-se como uma alternativa para diminuir as diferenças que existem no acesso às tecnologias digitais, mas que passam por questões de diferenças sociais, que podem refletir também no acesso e no domínio das tecnologias (Depoimento de professora do Curso de Jornalismo do Centro Universitário Franciscano - UNIFRA, em entrevista concedida à autora em 24/06/2006 - Registro de áudio). A inclusão digital é, hoje, uma realidade concreta em quase todas as escolas do país. Um exemplo disso é a ação do MEC que, desde o início deste ano, está enviando computadores para 117 escolas públicas de 84 municípios do RS. No entanto, o ponto nefrálgico está na questão de que $86 \%$ das escolas contempladas, até o momento, não estão utilizando as máquinas porque falta infra-estrutura nos locais. Algumas escolas não possuem laboratórios de informática e precisam construir um; outras não possuem linha telefônica; e, há escolas que não tem rede elétrica que suporte o uso dos computadores (MARIANO, 2006, p. 44-45).

6 Desde 1991, um grupo de pesquisadores já vem se debruçando sobre esse tema no Laboratório de Comunicação, Movimento e Mídia na Educação Física (LCMMEF) do CEFD/UFSM.

\section{REFERÊNCIAS}

BELLONI, M. L. Educação à distância. 2. ed. Campinas: Autores Associados, 2001. 
HATJE, M.et al. Esporte e sociedade: uma relação pautada pela mídia. Relatório de Iniciação Científica PIBIC/CNPq. Universidade Federal de Santa Maria, Santa Maria, 2004.

MARIANO, N. Tecnologia à espera de obras. Zero Hora, Porto Alegre, 30 de junho de 2006. Caderno Educação, p. 44-45.

Recebido: 27 de março de 2007

Aprovado: 23 de maio de 2007

Endereço para correspondência: paulacbianchi@yahoo.com.br

306 BIANCHI, P.; HATJE, M. A formação profissional em Educação Física ... 